\title{
Hybrid Implicit Iteration Process for a Finite Family of Non-Self-Nonexpansive Mappings in Uniformly Convex Banach Spaces
}

\author{
Qiaohong Jiang, Jinghai Wang, and Jianhua Huang \\ Institute of Mathematics and Computer Science, Fuzhou University, Fuzhou, Fujian 350002, China \\ Correspondence should be addressed to Qiaohong Jiang; fzdxjqh@126.com
}

Received 30 April 2014; Accepted 29 June 2014; Published 10 July 2014

Academic Editor: Luigi Muglia

Copyright (c) 2014 Qiaohong Jiang et al. This is an open access article distributed under the Creative Commons Attribution License, which permits unrestricted use, distribution, and reproduction in any medium, provided the original work is properly cited.

Weak and strong convergence theorems are established for hybrid implicit iteration for a finite family of non-self-nonexpansive mappings in uniformly convex Banach spaces. The results presented in this paper extend and improve some recent results.

\section{Introduction}

The convergence problem of an implicit (or nonimplicit) iterative process to a common fixed point for a finite family of nonexpansive mappings (or asymptotically nonexpansive mappings) in Hilbert spaces or uniformly convex Banach spaces has been considered by many authors (see [1-9]).

In 2001, Xu and Ori [1] introduced the following implicit iteration scheme for common fixed points of a finite family of nonexpansive mappings $\left\{T_{i}\right\}_{i=1}^{N}$ in Hilbert spaces:

$$
x_{n}=\alpha_{n} x_{n-1}+\left(1-\alpha_{n}\right) T_{n} x_{n}, \quad n \geq 1,
$$

where $T_{n}=T_{n(\bmod N)}$, and they proved the weak convergence theorem.

In 2005, Zeng and Yao [2] introduced the following implicit iteration process with a perturbed mapping $F$ in Hilbert space $H$.

For an arbitrary initial point $x_{0} \in H$, the sequence $\left\{x_{n}\right\}_{n=1}^{\infty}$ is generated as follows:

$$
x_{n}=\alpha_{n} x_{n-1}+\left(1-\alpha_{n}\right)\left[T_{n} x_{n}-\lambda_{n} \mu F\left(T_{n} x_{n}\right)\right], \quad n \geq 1,
$$

where $T_{n}=T_{n(\bmod N)}$.

Using this iteration process, they proved the following weak and strong convergence theorems for a family of nonexpansive mappings in Hilbert spaces.
Theorem 1 (see [2]). Let $H$ be a real Hilbert space and let $F$ : $H \rightarrow H$ be a mapping such that, for some constants $k, \eta>0$, $F$ is $k$-Lipschitzian and $\eta$-strongly monotone. Let $\left\{T_{n}\right\}_{n=1}^{N}$ be $N$ nonexpansive self-mappings of $H$ such that $\bigcap_{n=1}^{N}$ Fix $\left(T_{n}\right) \neq \emptyset$. Let $\mu \in\left(0,2 \eta / k^{2}\right)$ and $x_{0} \in H$. Let $\left\{\alpha_{n}\right\}_{n=1}^{\infty} \subset(0,1)$ and $\left\{\lambda_{n}\right\}_{n=1}^{\infty} \subset[0,1)$ satisfying conditions $\sum_{n=1}^{\infty} \lambda_{n}<\infty$ and $\alpha \leq$ $\alpha_{n} \leq \beta, n \geq 1$, for some $\alpha, \beta \in(0,1)$. Then the sequence $\left\{x_{n}\right\}_{n=1}^{\infty}$ defined by (2) converges weakly to a common fixed point of the mappings $\left\{T_{n}\right\}_{n=1}^{N}$.

Theorem 2 (see [2]). Let $H$ be a real Hilbert space and let $F$ : $H \rightarrow H$ be a mapping such that, for some constants $k, \eta>0$, $F$ is k-Lipschitzian and $\eta$-strongly monotone. Let $\left\{T_{n}\right\}_{n=1}^{N}$ be $N$ nonexpansive self-mappings of $H$ such that $\bigcap_{i=1}^{N} F i x\left(T_{i}\right) \neq \emptyset$. Let $\mu \in\left(0,2 \eta / k^{2}\right)$ and $x_{0} \in H$. Let $\left\{\alpha_{n}\right\}_{n=1}^{\infty} \subset(0,1)$ and $\left\{\lambda_{n}\right\}_{n=1}^{\infty} \subset[0,1)$ satisfying conditions $\sum_{n=1}^{\infty} \lambda_{n}<\infty$ and $\alpha \leq \alpha_{n} \leq \beta, n \geq 1$, for some $\alpha, \beta \in(0,1)$. Then the sequence $\left\{x_{n}\right\}_{n=1}^{\infty}$ defined by (2) converges strongly to a common fixed point of the mappings $\left\{T_{n}\right\}_{n=1}^{N}$ if and only if $\lim \inf _{n \rightarrow \infty} d\left(x_{n}, \bigcap_{n=1}^{N} \operatorname{Fix}\left(T_{n}\right)\right)=\emptyset$.

The purpose of this paper is to extend Theorems 1 and 2 from Hilbert spaces to uniformly convex Banach spaces and from self-mappings to non-self-mappings. Our results are more general and applicable than the results of Zeng and Yao [2] because the strong monotonicity condition imposed on $F$ by them is not required in this paper. 


\section{Preliminaries}

Throughout this paper, we assume that $E$ is a real Banach space. $T: D(T) \subseteq E \rightarrow E$ is a mapping, where $D(T)$ is the domain of $T . F(T)$ denotes the set of fixed points of a mapping $T$.

Recall that $E$ is said to satisfy Opial's condition [10], if, for each sequence $\left\{x_{n}\right\}$ in $E$, the condition that the sequence $x_{n} \rightarrow x$ weakly implies that

$$
\limsup _{n \rightarrow \infty}\left\|x_{n}-x\right\|<\limsup _{n \rightarrow \infty}\left\|x_{n}-y\right\|,
$$

for all $y \in E$ with $y \neq x$.

Definition 3. Let $K$ be a closed subset of $E$ and let $T: K \rightarrow E$, $f: E \rightarrow E$ be two mappings.

(1) $T$ is said to be demiclosed at the origin, if, for each sequence $\left\{x_{n}\right\}$ in $K$, the condition $x_{n} \rightarrow x_{0}$ weakly and $T x_{n} \rightarrow 0$ strongly implies $T x_{0}=0$.

(2) $T$ is said to be semicompact, if, for any bounded sequence $\left\{x_{n}\right\}$ in $K$, such that $\left\|x_{n}-T x_{n}\right\| \rightarrow$ $0(n \rightarrow \infty)$, there exists a subsequence $\left\{x_{n_{i}}\right\} \subset\left\{x_{n}\right\}$ converging to some $x^{*}$ in $K$.

(3) $T$ is said to be nonexpansive, if $\|T x-T y\| \leq\|x-y\|$ for any $x, y \in E$.

(4) $f$ is said to be $L$-Lipschitzian if there exists constant $L>0$ such that $\|f x-f y\| \leq L\|x-y\|$ for any $x, y \in E$.

Definition 4. A nonempty subset $K$ of $E$ is said to be a retract of $E$, if there exists a continuous mapping $r: E \rightarrow K$ such that $r x=x$, for any $x \in K$. And $r$ is called the retraction of $E$ onto $K$.

Remark 5 (see [3]). It is known that every nonempty closed convex subset $K$ of a uniformly convex Banach space $E$ is a retract of $E$ and the retraction $r$ is a nonexpansive mapping.

Suppose that $K$ is a nonempty closed convex subset of $E$, which is also a retract of $E$. Let $x_{0} \in K$ be any given point. Let $\left\{T_{1}, T_{2}, \ldots, T_{N}\right\}: K \rightarrow E$ be $N$ nonexpansive mappings with $T_{n}=T_{n(\bmod N)}$. Let $f: E \rightarrow E$ be an $L$-Lipschitzian mapping. Assume that $\left\{\alpha_{n}\right\}$ is a sequence in $(0,1)$ and $\left\{\lambda_{n}\right\} \subset[0,1)$, given $\mu>0$. Then the sequence $\left\{x_{n}\right\}$ defined by

$$
\begin{aligned}
x_{n} & =\alpha_{n} x_{n-1}+\left(1-\alpha_{n}\right) r T_{n}^{\lambda_{n}} x_{n} \\
& :=\alpha_{n} x_{n-1}+\left(1-\alpha_{n}\right) r\left[T_{n} x_{n}-\lambda_{n} \mu f\left(T_{n} x_{n}\right)\right], \quad n \geq 1,
\end{aligned}
$$

is called hybrid implicit iteration for a finite family of nonexpansive mappings $\left\{T_{1}, T_{2}, \ldots, T_{N}\right\}$ in Banach spaces, where $T_{n}^{n}=T_{n(\bmod N)}^{n}$ and $\mu$ is a fixed constant.

The purpose of this paper is to study weak and strong convergence of hybrid implicit iteration $\left\{x_{n}\right\}$ defined by (4) to a common fixed point of $\left\{T_{1}, T_{2}, \ldots, T_{N}\right\}: K \rightarrow E$ in Banach spaces. The results we obtained in this paper extend and improve the corresponding results of $\mathrm{Xu}$ and Ori [1], Zeng and Yao [2], and others.
In order to prove our main results of this paper, we need the following lemmas.

Lemma 6 (see [4]). Let $\left\{a_{n}\right\},\left\{b_{n}\right\}$, and $\left\{\delta_{n}\right\}$ be three nonnegative sequences satisfying

$$
a_{n+1} \leq\left(1+\delta_{n}\right) a_{n}+b_{n}, \quad \forall n=1,2, \ldots
$$

If $\sum_{n=1}^{\infty} \delta_{n}<\infty$ and $\sum_{n=1}^{\infty} b_{n}<\infty$, then $\lim _{n \rightarrow \infty} a_{n}$ exists.

Lemma 7 (see [5]). Let E be a uniformly convex Banach space. Let $b, c$ be two constants with $0<b<c<1$. Suppose that $\left\{t_{n}\right\}$ is a sequence in $[b, c]$ and $\left\{x_{n}\right\},\left\{y_{n}\right\}$ are two sequences in $E$. Then the conditions

$$
\begin{gathered}
\lim _{n \rightarrow \infty}\left\|t_{n} x_{n}+\left(1-t_{n}\right) y_{n}\right\|=d, \\
\limsup _{n \rightarrow \infty}\left\|x_{n}\right\| \leq d, \\
\limsup _{n \rightarrow \infty}\left\|y_{n}\right\| \leq d
\end{gathered}
$$

imply that $\lim _{n \rightarrow \infty}\left\|x_{n}-y_{n}\right\|=0$, where $d \geq 0$ is some constant.

Lemma 8 (see [6]). Let $K$ be a nonempty closed convex subset of real Banach space $E$ and $T: K \rightarrow E$ a nonexpansive mapping. If $T$ has a fixed point, then $I-T$ is demiclosed at zero, where $I$ is the identity mapping of $E$.

\section{Main Results}

Theorem 9. Suppose that $E$ is a real uniformly convex Banach space satisfying Opial's condition and $K$ is a nonempty closed convex subset of $E$ with a nonexpansive retraction $r: E \rightarrow K$. Let $\left\{T_{1}, T_{2}, \ldots, T_{N}\right\}: K \rightarrow E$ be $N$ nonexpansive mappings with $F=\bigcap_{n=1}^{N} F\left(T_{n}\right) \neq \emptyset$ and let $f: E \rightarrow E$ be an $L$ Lipschitzian mapping. Assume that $\left\{\alpha_{n}\right\}$ is a sequence in $(0,1)$ and $\left\{\lambda_{n}\right\} \subset[0,1)$ satisfying the following conditions:

(i) $\sum_{n=1}^{\infty} \lambda_{n}<\infty$;

(ii) there exist constants $\tau_{1}, \tau_{2} \in(0,1)$ such that

$$
\tau_{1} \leq\left(1-\alpha_{n}\right) \leq \tau_{2}, \quad \forall n \geq 1
$$

Then, the implicit iterative process $\left\{x_{n}\right\}$ defined by (4) converges weakly to a common fixed point of $\left\{T_{1}, T_{2}, \ldots, T_{N}\right\}$ in $E$.

Proof. Since $F=\bigcap_{n=1}^{N} F\left(T_{i}\right) \neq \emptyset$, for each $q \in F$, we have

$$
\begin{aligned}
\left\|x_{n}-q\right\|= & \left\|\alpha_{n}\left(x_{n-1}-q\right)+\left(1-\alpha_{n}\right)\left(r T_{n}^{\lambda_{n}} x_{n}-q\right)\right\| \\
= & \left\|\alpha_{n}\left(x_{n-1}-q\right)+\left(1-\alpha_{n}\right)\left(r T_{n}^{\lambda_{n}} x_{n}-r q\right)\right\| \\
\leq & \alpha_{n}\left\|x_{n-1}-q\right\|+\left(1-\alpha_{n}\right)\left\|T_{n}^{\lambda_{n}} x_{n}-q\right\| \\
\leq & \alpha_{n}\left\|x_{n-1}-q\right\|+\left(1-\alpha_{n}\right)\left\|T_{n} x_{n}-q\right\| \\
& +\left(1-\alpha_{n}\right) \lambda_{n} \mu\left\|f\left(T_{n} x_{n}\right)\right\|
\end{aligned}
$$




$$
\begin{aligned}
\leq & \alpha_{n}\left\|x_{n-1}-q\right\|+\left(1-\alpha_{n}\right)\left\|x_{n}-q\right\| \\
& +\left(1-\alpha_{n}\right) \lambda_{n} \mu\left\|f\left(T_{n} x_{n}\right)-f(q)\right\| \\
& +\left(1-\alpha_{n}\right) \lambda_{n} \mu\|f(q)\| \\
\leq & \alpha_{n}\left\|x_{n-1}-q\right\|+\left(1-\alpha_{n}\right)\left\|x_{n}-q\right\| \\
& +\lambda_{n} \mu L\left\|x_{n}-q\right\|+\lambda_{n} \mu\|f(q)\| .
\end{aligned}
$$

Simplifying we have

$$
\left\|x_{n}-q\right\| \leq\left\|x_{n-1}-q\right\|+\frac{\lambda_{n} \mu L}{\alpha_{n}}\left\|x_{n}-q\right\|+\frac{\lambda_{n} \mu}{\alpha_{n}}\|f(q)\| .
$$

By condition (ii), $1-\tau_{2} \leq \alpha_{n}$; hence from (9) we have

$$
\left\|x_{n}-q\right\| \leq\left\|x_{n-1}-q\right\|+\frac{\lambda_{n} \mu L}{1-\tau_{2}}\left\|x_{n}-q\right\|+\frac{\lambda_{n} \mu}{1-\tau_{2}}\|f(q)\| .
$$

By condition (i), we know that $\lambda_{n} \rightarrow 0$ and $\lambda_{n} \mu L \rightarrow 0$ as $n \rightarrow \infty$; therefore there exists a positive integer $n_{0}$ such that $\lambda_{n} \mu L \leq\left(1-\tau_{2}\right) / 2$, for all $n \geq n_{0}$; then we have

$$
\begin{aligned}
\left\|x_{n}-q\right\| \leq & \frac{1-\tau_{2}}{1-\tau_{2}-\lambda_{n} \mu L}\left\|x_{n-1}-q\right\| \\
& +\frac{\lambda_{n} \mu}{1-\tau_{2}-\lambda_{n} \mu L}\|f(q)\| \\
= & \left(1+\frac{\lambda_{n} \mu L}{1-\tau_{2}-\lambda_{n} \mu L}\right)\left\|x_{n-1}-q\right\| \\
& +\frac{\lambda_{n} \mu}{1-\tau_{2}-\lambda_{n} \mu L}\|f(q)\| .
\end{aligned}
$$

It follows from (11) that

$$
\begin{array}{r}
\left\|x_{n}-q\right\| \leq\left(1+\frac{2 \lambda_{n} \mu L}{1-\tau_{2}}\right)\left\|x_{n-1}-q\right\|+\frac{2 \lambda_{n} \mu}{1-\tau_{2}}\|f(q)\|, \\
\forall n \geq n_{0} .
\end{array}
$$

Taking $a_{n}=\left\|x_{n}-q\right\|, \delta_{n}=2 \lambda_{n} \mu L /\left(1-\tau_{2}\right)$, and $b_{n}=\left(2 \lambda_{n} \mu /(1-\right.$ $\left.\left.\tau_{2}\right)\right)\|f(q)\|$ and by using $\sum_{n=1}^{\infty} \lambda_{n}<\infty$, it is easy to see that

$$
\sum_{n=1}^{\infty} \delta_{n}<\infty, \quad \sum_{n=1}^{\infty} b_{n}<\infty .
$$

It follows from Lemma 6 that $\lim _{n \rightarrow \infty}\left\|x_{n}-q\right\|$ exists for each $q \in F$. Hence, there exists $M>0$, such that

$$
\left\|x_{n}-q\right\| \leq M, \quad n \geq 0 .
$$

We can assume that

$$
\lim _{n \rightarrow \infty}\left\|x_{n}-q\right\|=d,
$$

where $d \geq 0$ is some number. Since $\left\{\left\|x_{n}-q\right\|\right\}$ is a convergent sequence, $\left\{x_{n}\right\}$ is a bounded sequence in $K$. Since

$$
\left\|x_{n}-q\right\|=\left\|\alpha_{n}\left(x_{n-1}-q\right)+\left(1-\alpha_{n}\right)\left(r T_{n}^{\lambda_{n}} x_{n}-q\right)\right\|,
$$

by condition (i) and (8) and (15), that

$$
\begin{aligned}
\limsup _{n \rightarrow \infty}\left\|r T_{n}^{\lambda_{n}} x_{n}-q\right\|= & \limsup _{n \rightarrow \infty}\left\|r T_{n}^{\lambda_{n}} x_{n}-r q\right\| \\
\leq & \limsup _{n \rightarrow \infty}\left\|T_{n}^{\lambda_{n}} x_{n}-q\right\| \\
\leq & \limsup _{n \rightarrow \infty}\left\|T_{n} x_{n}-T_{n} q\right\| \\
& +\limsup _{n \rightarrow \infty} \lambda_{n} \mu\left\|f\left(T_{n} x_{n}\right)-f\left(T_{n} q\right)\right\| \\
& +\limsup _{n \rightarrow \infty} \lambda_{n} \mu\left\|f\left(T_{n} q\right)\right\| \\
\leq & \limsup _{n \rightarrow \infty}\left\|x_{n}-q\right\| \\
& +\limsup _{n \rightarrow \infty} \lambda_{n} \mu L\left\|x_{n}-q\right\| \\
& +\limsup _{n \rightarrow \infty} \lambda_{n} \mu\|f(q)\| \leq d .
\end{aligned}
$$

Since $E$ is a uniformly convex Banach space, from (15)-(17) and Lemma 7 we know that

$$
\lim _{n \rightarrow \infty}\left\|x_{n-1}-r T_{n}^{\lambda_{n}} x_{n}\right\|=0 .
$$

By (18), we have that

$$
\begin{aligned}
\left\|x_{n}-x_{n-1}\right\| & =\left\|\left(\alpha_{n}-1\right) x_{n-1}+\left(1-\alpha_{n}\right) r T_{n}^{\lambda_{n}} x_{n}\right\| \\
& \leq\left(1-\alpha_{n}\right)\left\|x_{n-1}-r T_{n}^{\lambda_{n}} x_{n}\right\| \longrightarrow 0, \quad(n \longrightarrow \infty) .
\end{aligned}
$$

It follows from (18) and (19) that

$$
\begin{aligned}
& \lim _{n \rightarrow \infty}\left\|x_{n}-r T_{n}^{\lambda_{n}} x_{n}\right\| \leq \lim _{n \rightarrow \infty}(\left\|x_{n}-x_{n-1}\right\| \\
&\left.+\left\|x_{n-1}-r T_{n}^{\lambda_{n}} x_{n}\right\|\right)=0 \\
& \lim _{n \rightarrow \infty}\left\|x_{n}-x_{n+j}\right\|=0, \quad \forall j=1,2, \ldots, N
\end{aligned}
$$

By (14), we know

$$
\begin{aligned}
\left\|f\left(T_{n} x_{n}\right)\right\| & \leq\left\|f\left(T_{n} x_{n}\right)-f(q)\right\|+\|f(q)\| \\
& \leq L\left\|x_{n}-q\right\|+\|f(q)\| \leq L M+\|f(q)\| .
\end{aligned}
$$

From (20), (22), and condition (i) we have

$$
\begin{aligned}
\lim _{n \rightarrow \infty} & \left\|x_{n}-T_{n} x_{n}\right\| \\
\quad \leq & \lim _{n \rightarrow \infty}\left(\left\|x_{n}-T_{n}^{\lambda_{n}} x_{n}\right\|+\left\|T_{n}^{\lambda_{n}} x_{n}-T_{n} x_{n}\right\|\right) \\
\quad \leq & \lim _{n \rightarrow \infty}\left(\left\|x_{n}-T_{n}^{\lambda_{n}} x_{n}\right\|+\lambda_{n} \mu(L M+\|f(q)\|)\right)=0 .
\end{aligned}
$$


Consequently, for any $j=1,2, \ldots, N$, from (21) and (23) we have

$$
\begin{aligned}
\left\|x_{n}-T_{n+j} x_{n}\right\| \leq & \left\|x_{n}-x_{n+j}\right\|+\left\|x_{n+j}-T_{n+j} x_{n+j}\right\| \\
& +\left\|T_{n+j} x_{n+j}-T_{n+j} x_{n}\right\| \\
\leq & 2\left\|x_{n}-x_{n+j}\right\|+\left\|x_{n+j}-T_{n+j} x_{n+j}\right\| \longrightarrow 0, \\
& (n \longrightarrow \infty) .
\end{aligned}
$$

This implies that the sequence

$$
\bigcup_{j=1}^{N}\left\{\left\|x_{n}-T_{n+j} x_{n}\right\|\right\}_{n=1}^{\infty} \longrightarrow 0 \quad(n \longrightarrow \infty) .
$$

Since, for each $l=1,2, \ldots, N,\left\{\left\|x_{n}-T_{l} x_{n}\right\|\right\}_{n=1}^{\infty}$ is a subsequence of $\bigcup_{j=1}^{N}\left\{\left\|x_{n}-T_{n+j} x_{n}\right\|\right\}_{n=1}^{\infty}$, therefore we have

$$
\lim _{n \rightarrow \infty}\left\|x_{n}-T_{l} x_{n}\right\|=0, \quad \forall l=1,2, \ldots N .
$$

Since $E$ is uniformly convex, every bounded subset of $E$ is weakly compact. Since $\left\{x_{n}\right\}$ is a bounded sequence in $E$, there exists a subsequence $\left\{x_{n_{j}}\right\} \subset\left\{x_{n}\right\}$ such that $\left\{x_{n_{j}}\right\}$ converges weakly to $u \in E$. From (26) we have

$$
\lim _{n \rightarrow \infty}\left\|x_{n_{j}}-T_{l} x_{n_{j}}\right\|=0, \quad \forall l=1,2, \ldots N .
$$

By Lemma 8, we know that $u \in F\left(T_{l}\right)$. By the arbitrariness of $l \in\{1,2, \ldots N\}$, we have that $u \in F=\bigcap_{l=1}^{N} F\left(T_{i}\right)$.

Suppose that there exists some subsequence $\left\{x_{n_{k}}\right\} \subset\left\{x_{n}\right\}$ such that $x_{n_{k}} \rightarrow v \in E$ weakly and $v \neq u$. From Lemma $8, v \in$ $F$. By (12) we know that $\lim _{n \rightarrow \infty}\left\|x_{n}-u\right\|$ and $\lim _{n \rightarrow \infty}\left\|x_{n}-v\right\|$ exist. Since $E$ satisfies Opial's condition, we have

$$
\begin{aligned}
\lim _{n \rightarrow \infty}\left\|x_{n}-u\right\| & =\lim _{j \rightarrow \infty}\left\|x_{n_{j}}-u\right\|<\lim _{j \rightarrow \infty}\left\|x_{n_{j}}-v\right\| \\
& =\lim _{n \rightarrow \infty}\left\|x_{n}-v\right\|=\lim _{k \rightarrow \infty}\left\|x_{n_{k}}-v\right\| \\
& <\lim _{k \rightarrow \infty}\left\|x_{n_{k}}-u\right\|=\lim _{n \rightarrow \infty}\left\|x_{n}-u\right\|,
\end{aligned}
$$

which is a contradiction. Hence $u=v$. This implies that $\left\{x_{n}\right\}$ converges weakly to a common fixed point of $\left\{T_{1}, T_{2}, \ldots, T_{N}\right\}$ in $E$.

Theorem 10. Suppose that $E$ is a real uniformly convex Banach space and $K$ is a nonempty closed convex nonexpansive retract of $E$ with $r: E \rightarrow K$ as a nonexpansive retraction. Let $\left\{T_{1}, T_{2}, \ldots, T_{N}\right\}: K \rightarrow E$ be $N$ nonexpansive mappings with $F=\bigcap_{n=1}^{N} F\left(T_{n}\right) \neq \emptyset$ and let $f: E \rightarrow E$ be an $L$ Lipschitzian mapping. Assume that $\left\{\alpha_{n}\right\}$ is a sequence in $(0,1)$ and $\left\{\lambda_{n}\right\} \subset[0,1)$ satisfying the following conditions:

(i) $\sum_{n=1}^{\infty} \lambda_{n}<\infty$;

(ii) there exist constants $\tau_{1}, \tau_{2} \in(0,1)$ such that

$$
\tau_{1} \leq\left(1-\alpha_{n}\right) \leq \tau_{2}, \quad \forall n \geq 1
$$

Then, the implicit iterative process $\left\{x_{n}\right\}$ defined by (4) converges strongly to a common fixed point of $\left\{T_{1}, T_{2}, \ldots, T_{N}\right\}$ if and only if $\lim \inf _{n \rightarrow \infty} d\left(x_{n}, F\left(T_{l}\right)\right)=0$ (for all $\left.l=1,2, \ldots, N\right)$.

Proof. From (12) and (14) in the proof of Theorem 9, we have

$$
\begin{aligned}
\left\|x_{n}-q\right\| \leq & \left(1+\delta_{n}\right)\left\|x_{n-1}-q\right\|+b_{n} \leq\left\|x_{n-1}-q\right\| \\
& +M \delta_{n}+b_{n}=\left\|x_{n-1}-q\right\|+\beta_{n},
\end{aligned}
$$

where $\delta_{n}=2 \lambda_{n} \mu L /\left(1-\tau_{2}\right), b_{n}=\left(2 \lambda_{n} \mu /\left(1-\tau_{2}\right)\right)\|f(q)\|$, and $\beta_{n}=M \delta_{n}+b_{n}$. Hence, $d\left(x_{n}, F\right) \leq d\left(x_{n-1}, F\right)+\beta_{n}$. Since $\sum_{n=1}^{\infty} \beta_{n}<\infty$, it follows from Lemma 6 that $\lim _{n \rightarrow \infty} d\left(x_{n}, F\right)$ exists.

If $\left\{x_{n}\right\}_{n=1}^{\infty}$ converges strongly to a common fixed point $p$ of $\left\{T_{1}, T_{2}, \ldots, T_{N}\right\}$, then $\lim _{n \rightarrow \infty}\left\|x_{n}-p\right\|=0$. Since

$$
0 \leq d\left(x_{n}, F\right) \leq\left\|x_{n}-p\right\|
$$

we know that $\liminf _{n \rightarrow \infty} d\left(x_{n}, F\right)=0$.

Conversely, suppose $\liminf _{n \rightarrow \infty} d\left(x_{n}, F\right)=0$; then $\lim _{n \rightarrow \infty} d\left(x_{n}, F\right)=0$. Moreover, we have $\sum_{n=1}^{\infty} \beta_{n}<\infty$; thus for arbitrary $\epsilon>0$, there exists a positive integer $N$ such that $d\left(x_{n}, F\right)<\epsilon / 4$ and $\sum_{j=n}^{\infty} \beta_{j}<\epsilon / 4$ for all $n \geq N$. It follows from (30) that, for all $n, m \geq N$ and for all $p \in F$, we have

$$
\begin{aligned}
\left\|x_{n}-x_{m}\right\| & \leq\left\|x_{n}-p\right\|+\left\|x_{m}-p\right\| \\
& \leq\left\|x_{N}-p\right\|+\sum_{j=N+1}^{n} \beta_{j}+\left\|x_{N}-p\right\|+\sum_{j=N+1}^{m} \beta_{j} \\
& \leq 2\left\|x_{N}-p\right\|+2 \sum_{j=N}^{\infty} \beta_{j} .
\end{aligned}
$$

Taking infimum over all $p \in F$, we obtain

$$
\left\|x_{n}-x_{m}\right\| \leq 2 d\left(x_{N}, F\right)+2 \sum_{j=N}^{\infty} \beta_{j}<\epsilon, \quad \forall n, m \geq N .
$$

Thus, $\left\{x_{n}\right\}_{n=1}^{\infty}$ is a Cauchy sequence. Letting $\lim _{n \rightarrow \infty} x_{n}=u$, then, from Lemma 8 , we have $u \in F$. This completes the proof of the theorem.

Theorem 11. Suppose that $E$ is a real uniformly convex Banach space and $K$ is a nonempty closed convex nonexpansive retract of $E$ with $r: E \rightarrow K$ as a nonexpansive retraction. Let $\left\{T_{1}, T_{2}, \ldots, T_{N}\right\}: K \rightarrow E$ be $N$ nonexpansive mappings with $F=\bigcap_{n=1}^{N} F\left(T_{n}\right) \neq \emptyset$ and at least there exists a $T_{l}, 1 \leq l \leq N$, which is semicompact. Let $f: E \rightarrow E$ be L-Lipschitzian mapping. Assume that $\left\{\alpha_{n}\right\}$ is a sequence in $(0,1)$ and $\left\{\lambda_{n}\right\} \subset[0,1)$ satisfying the following conditions:

(i) $\sum_{n=1}^{\infty} \lambda_{n}<\infty$;

(ii) there exist constants $\tau_{1}, \tau_{2} \in(0,1)$ such that

$$
\tau_{1} \leq\left(1-\alpha_{n}\right) \leq \tau_{2}, \quad \forall n \geq 1 .
$$

Then, the implicit iterative process $\left\{x_{n}\right\}$ defined by (4) converges strongly to a common fixed point of $\left\{T_{1}, T_{2}, \ldots, T_{N}\right\}$ in $E$. 
Proof. From the proof of Theorem 9, $\left\{x_{n}\right\}$ is bounded, and $\lim _{n \rightarrow \infty}\left\|x_{n}-T_{l} x_{n}\right\|=0$, for all $l=1,2, \ldots N$. We especially have

$$
\lim _{n \rightarrow \infty}\left\|x_{n}-T_{1} x_{n}\right\|=0
$$

By the assumption of Theorem 11, we may assume that $T_{1}$ is semicompact, without loss of generality. Then, it follows from (35) that there exists a subsequence $\left\{x_{n_{k}}\right\}$ of $\left\{x_{n}\right\}$ such that $\left\{x_{n_{k}}\right\}$ converges strongly to $p \in K$. Thus from (26) we have

$$
\begin{array}{r}
\left\|p-T_{l} p\right\|=\lim _{k \rightarrow \infty}\left\|x_{n_{k}}-T_{l} x_{n_{k}}\right\|=\lim _{n \rightarrow \infty}\left\|x_{n}-T_{l} x_{n}\right\|=0, \\
\forall l=1,2, \ldots N .
\end{array}
$$

This implies that $p \in F$. In addition, since $\lim _{n \rightarrow \infty}\left\|x_{n}-p\right\|$ exists, therefore $\lim _{n \rightarrow \infty}\left\|x_{n}-p\right\|=0$; that is, $\left\{x_{n}\right\}$ converges strongly to a fixed point of $\left\{T_{1}, T_{2}, \ldots, T_{N}\right\}$ in $E$. The proof is completed.

\section{Conflict of Interests}

The authors declare that there is no conflict of interests regarding the publication of this paper.

\section{Authors' Contribution}

The main idea of this paper was proposed by Qiaohong Jiang. All authors contributed equally to the writing of this paper. All authors read and approved the final paper.

\section{Acknowledgment}

The research was supported by the Fujian Nature Science Foundation under Grant no. 2014J01008.

\section{References}

[1] H. Xu and R. G. Ori, "An implicit iteration process for nonexpansive mappings," Numerical Functional Analysis and Optimization, vol. 22, no. 5-6, pp. 767-773, 2001.

[2] L.-C. Zeng and J.-C. Yao, "Implicit iteration scheme with perturbed mapping for common fixed points of a finite family of nonexpansive mappings," Nonlinear Analysis: Theory, Methods \& Applications, vol. 64, no. 11, pp. 2507-2515, 2006.

[3] R. P. Agarwal and M. Meehan, Fixed Point Theory and Applications, Cambridge Tracts in Mathematics, Cambridge University Press, 2005.

[4] K. K. Tan and H. K. Xu, "Approximating fixed points of nonexpansive mappings by the Ishikawa iteration process," Journal of Mathematical Analysis and Applications, vol. 178, no. 2, pp. 301-308, 1993.

[5] J. Schu, "Weak and strong convergence to fixed points of asymptotically nonexpansive mappings," Bulletin of the Australian Mathematical Society, vol. 43, no. 1, pp. 153-159, 1991.

[6] K. Goebel and W. A. Kirk, Topics in Metric Fixed Point Theory, vol. 28 of Cambridge Studies in Advanced Mathematics, Cambridge University Press, Cambridge, Mass, USA, 1990.
[7] S. S. Chang, K. K. Tan, H. W. J. Lee, and C. K. Chan, "On the convergence of implicit iteration process with error for a finite family of asymptotically nonex pansive mappings in Banach spaces," Journal of Mathematical Analysis and Applications, vol. 313, pp. 273-283, 2006.

[8] H. Xu, "Viscosity approximation methods for nonexpansive mappings," Journal of Mathematical Analysis and Applications, vol. 298, no. 1, pp. 279-291, 2004.

[9] Y. Yao and J. Yao, "On modified iterative method for nonexpansive mappings and monotone mappings," Applied Mathematics and Computation, vol. 186, no. 2, pp. 1551-1558, 2007.

[10] Z. Opial, "Weak convergence of the sequence of successive approximations for nonexpansive mappings," Bulletin of the American Mathematical Society, vol. 73, pp. 591-597, 1967. 


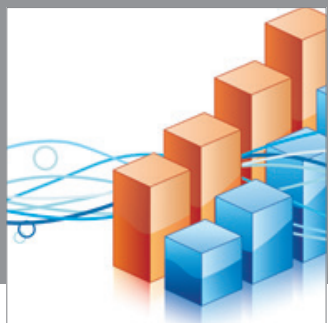

Advances in

Operations Research

mansans

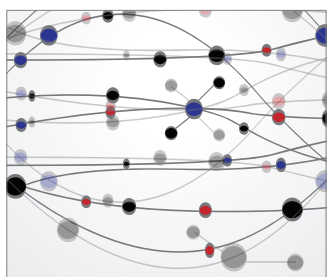

The Scientific World Journal
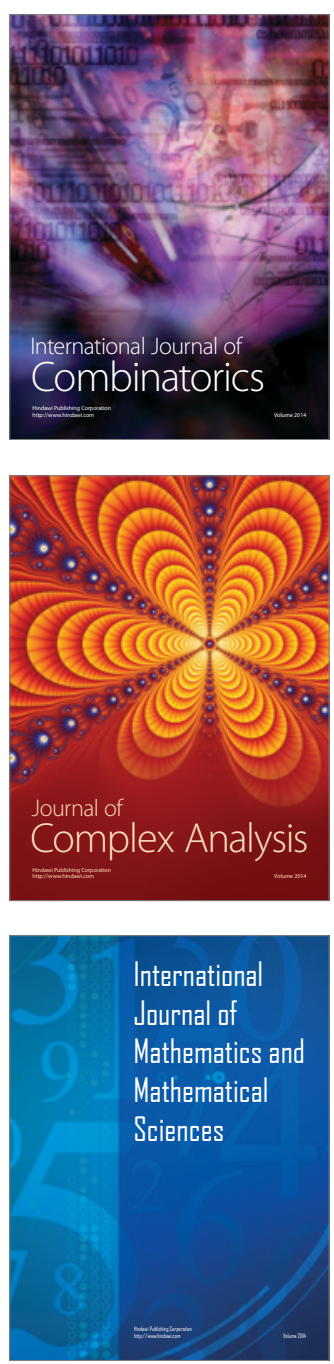
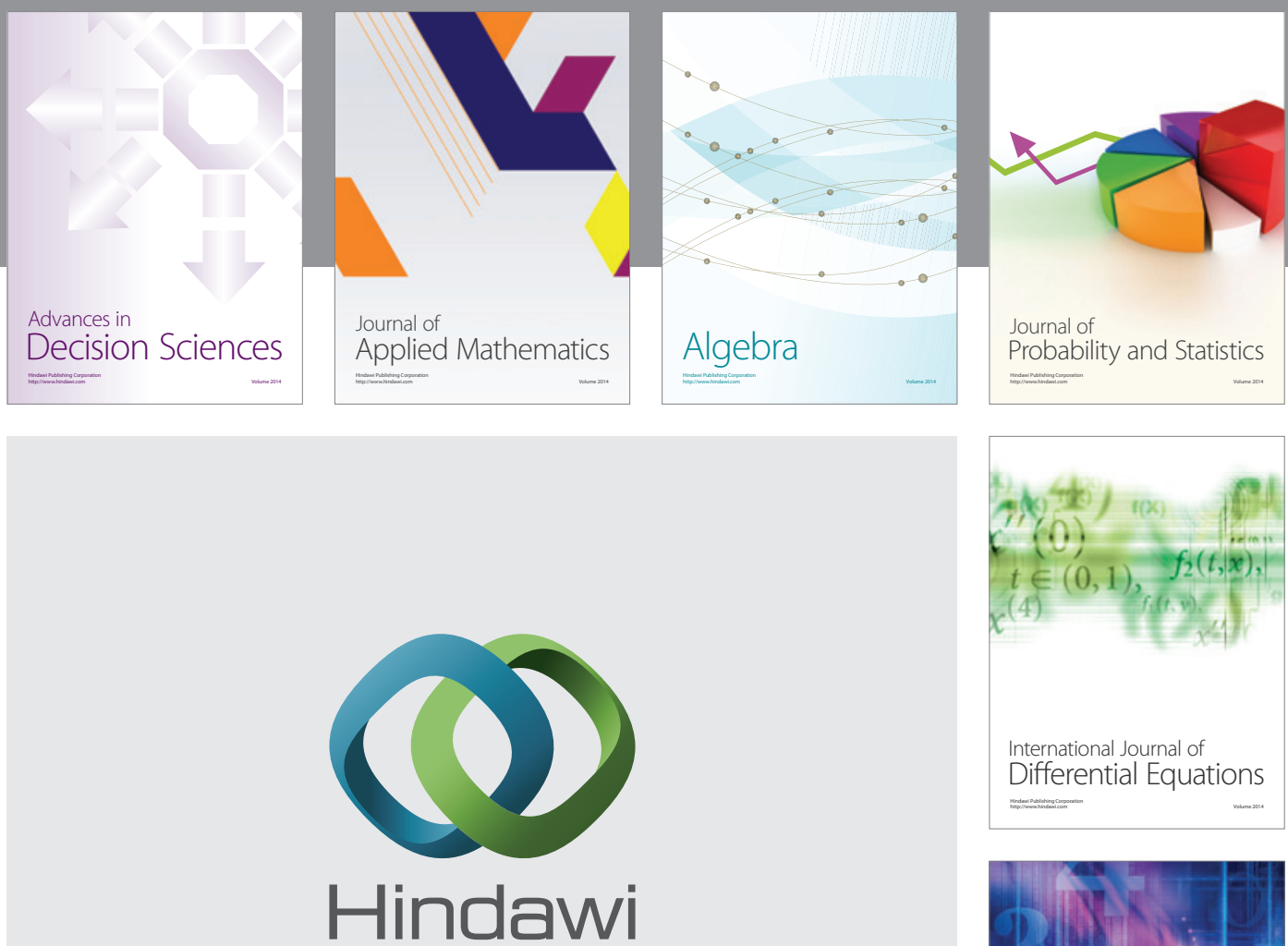

Submit your manuscripts at http://www.hindawi.com
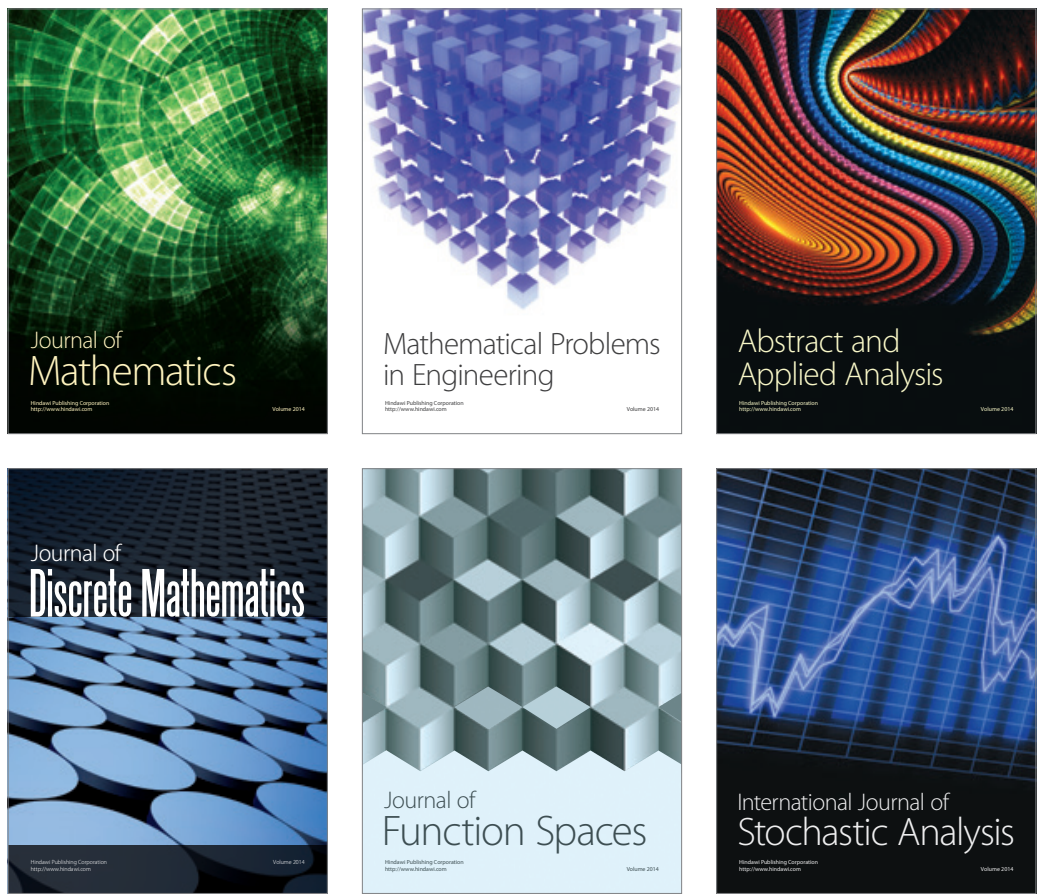

Journal of

Function Spaces

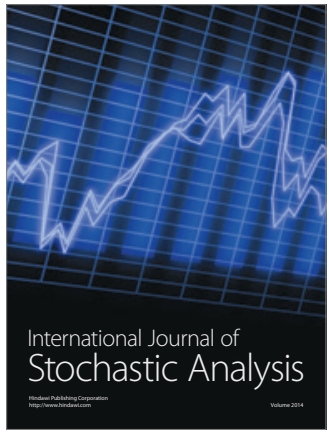

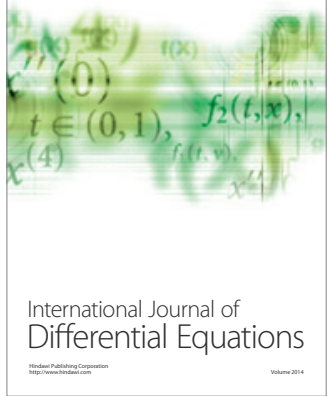
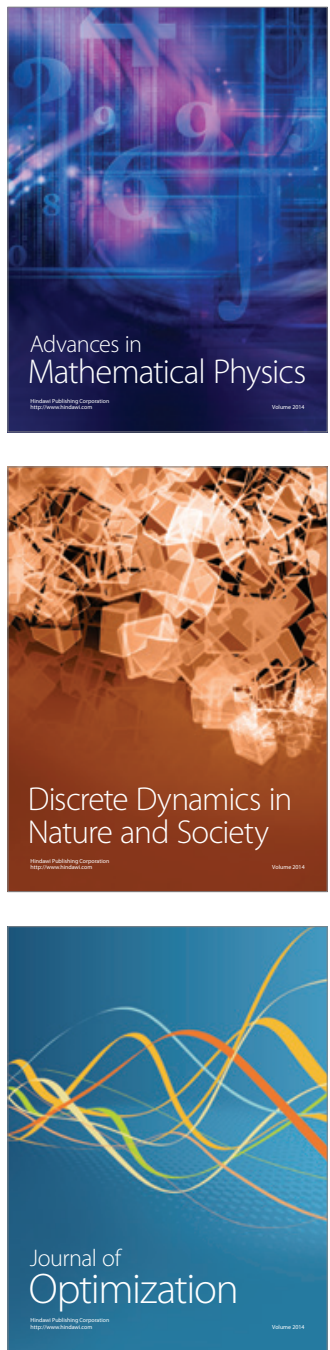